This is the preprint of a manuscript accepted for publication in the International Journal of Behavioral Development.

Please cite this work as:

Mund, M. \& Neyer, F. J. (in press). Loneliness effects on personality. International Journal of Behavioral Development. doi:10.1177/0165025418800224

This version might not exactly replicate the final version published in the journal. It is not the copy of record. 


\title{
Loneliness Effects on Personality
}

\author{
Marcus Mund and Franz J. Neyer \\ Friedrich-Schiller-Universität Jena
}

\begin{abstract}
Individuals feel lonely when they perceive a discrepancy between the desired and actually experienced quantity and quality of social relationships. Prior research has demonstrated the importance of loneliness for various health-related aspects. In the present article, we extend the existing literature on loneliness by investigating its role for predicting personality traits and their development from late adolescence to early midlife. Using data from a representative German sample $(\mathrm{N}=12,402)$ sampling individuals from three different birth cohorts, we found loneliness to predict the levels of all Big Five traits but Openness five years later. The effects of loneliness on the development of neuroticism and extraversion reached statistical significance but were only marginal in terms of effect size. Furthermore, we found that a self-regulatory focus geared to the prevention of negative events mediated the effects of loneliness on later levels of the Big Five.
\end{abstract}

Keywords: loneliness, personality traits, personality development, selfregulatory focus

Individuals feel lonely when they do not have as many and as close social relationships as they desire (de Jong Gierveld, 1998, Ernst \& Cacioppo, 1999, Hawkley \& Cacioppo, 2010). Feeling lonely is consequential for individuals and has been identified as a predictor of a broad array of health-related outcomes including objective health risk factors (e.g., elevated blood pressure, elevated number of inflammatory markers; Hawkley, Burleson, Berntson, \& Cacioppo, 2003 Hawkley, Thisted, Masi, \& Cacioppo, 2010 Shankar, McMunn, Banks, \& Steptoe, 2011), health-relevant behaviors (e.g., smoking, physical inactivity, excessive alcohol consumption; Åkerlind \&

Marcus Mund and Franz J. Neyer, Institut für Psychologie, Friedrich-Schiller-Universität Jena, Germany.

Correspondence concerning this article should be addressed to Marcus Mund, Friedrich-SchillerUniversität Jena, Institut für Psychologie, Humboldtstraße 11, D-07743 Jena, E-mail: marcus.mund@gmail.com 
Hörnquist, 1992; DeWall \& Pond, 2011; Hawkley, Thisted, \& Cacioppo, 2009 Lauder, Mummery, Jones, \& Caperchione, 2006 Shankar et al., 2011), and depression (Cacioppo, Hawkley, \& Thisted, 2010 Cacioppo, Hughes, Waite, Hawkley, \& Thisted, 2006: Qualter, Brown, Munn, \& Rotenberg, 2010; Russell, Cutrona, Rose, \& Yurko, 1984; Vanhalst et al., 2012).

Beyond such specific effects on aspects of health, loneliness might also affect personality in a broader sense. The kindling effect, for instance, describes how depressive episodes leave scars in an individual's personality by permanently increasing neuroticism (Kendler, Neale, Kessler, Heath, \& Eaves, 1993 Monroe \& Harkness, 2005). If depression affects personality in this way, it is well conceivable that loneliness as one of its key predictors (Cacioppo et al., 2006; Hawkley \& Cacioppo, 2010; Qualter et al., 2010, Vanhalst et al., 2012) affects personality traits in a similar way. Furthermore, many of the behavioral risk factors that loneliness has been found to be associated with (e.g., physical inactivity, smoking, excessive alcohol consumption) have been found to be likewise associated with personality trait levels (Bogg \& Roberts, 2004; Hakulinen, Elovainio, et al., 2015. Hakulinen, Hintsanen, et al., 2015. Zvolensky, Taha, Bono, \& Goodwin, 2015) and personality trait development (Stephan, Sutin, \& Terraciano, 2014), thereby again pointing to a direct association between personality and loneliness.

Indeed, prior research has found associations between loneliness and the Big Five personality traits of neuroticism, extraversion, openness, agreeableness, and conscientiousness. Specifically, elevated levels of loneliness have been found to be particularly related to higher levels of neuroticism and lower levels of both extraversion and agreeableness (Hensley et al., 2012; Saklofske \& Yackulic, 1989; Stokes, 1985, Teppers et al., 2013 van der Aa et al., 2009; Vanhalst, Goossens, Luyckx, Scholte, \& Engels, 2013; Vanhalst et al., 2012). By contrast, prior findings for openness and conscientiousness are inconsistent. For openness, previous studies have reported both negative associations (van der Aa et al., 2009 Vanhalst et al., 2012) and no association (Teppers et al., 2013 Vanhalst et al., 2013) with loneliness. With regard to conscientiousness, loneliness has been found to be unrelated (Teppers et al., 2013 Vanhalst et al., 2013) positively related (Teppers et al., 2013, Vanhalst et al., 2012), or negatively related (van der Aa et al., 2009) with loneliness.

These findings, which are based on cross-sectional or short-term longitudinal studies, have recently been extended by Mund and Neyer (2016), who have examined the association between the Big Five traits and loneliness over a period of 15 years from young adulthood to early midlife. They have found increased levels of loneliness to predict higher levels of neuroticism and lower levels of both extraversion and conscientiousness 15 years later, while only neuroticism at baseline was predictive of later levels of loneliness. Furthermore, Mund and Neyer (2016) found higher levels of loneliness at baseline to predict slower decreases in neuroticism as well as slower increases in conscientiousness from young adulthood to early midlife. As the study by Mund and Neyer (2016) was the first to show these longitudinal associations between loneli- 
ness and personality trait development across adulthood, several questions remained unanswered.

First, the results by Mund and Neyer (2016) were based on a sample of 654 German adults aged between 18 and 30 years at the first measurement occasion. By using a sample that invokes multiple more age-homogeneous subsamples, it might be possible to identify specific age periods in which loneliness is particularly closely tied to personality development. This might shed further light on the degree of generalizibilty of the original findings and might further indicate whether a sensitive phase in personality development exists, in which the effects of loneliness are more detrimental than in other age periods.

Furthermore, Mund and Neyer (2016) used the de Jong Gierveld Loneliness Scale to assess loneliness in their participants. This scale is a representative of indirect measures of loneliness. Such indirect measures avoid references to the construct under scrutiny by avoiding terms such as "lonely" or "loneliness" in their items, since these terms have been found to be associated with a stigma (Ernst \& Cacioppo, 1999; Perlman \& Peplau, 1981; Rotenberg, 1998 Rotenberg \& Kmill, 1992) and might evoke social desirable responding. Direct measures (e.g., "How often do you feel lonely?"), in contrast, require a self-labelling of the participants as lonely. Previous research has shown that direct and indirect measures of loneliness yield different results concerning the prevalence of loneliness and its demographic correlates. Specifically, when using direct measures, individuals appear to be less inclined to admit loneliness, which leads to a lower estimated prevalence in comparison to indirect measures (Shiovitz-Ezra \& Ayalon, 2012 Victor, Grenade, \& Boldy, 2005). Furthermore, women have been found to score higher than men on direct measures of loneliness, but this difference is absent when indirect measures are used (Borys \& Perlman, 1985, Pinquart \& Sörensen, 2001). Similarly, while no association between loneliness and education has been found with direct measures, less educated individuals have been found to report higher levels of loneliness when an indirect measure was employed (Shiovitz-Ezra \& Ayalon, 2012). Thus, in order to examine whether the results reported by Mund and Neyer (2016) are robust and generalizable, it is important to investigate effects of loneliness on personality traits with a direct measure of loneliness as well.

Finally, the study by Mund and Neyer (2016) provided first evidence of loneliness effects on personality traits across adulthood. However, their study remained silent about mechanisms possibly mediating these effects. One possible mechanism underlying the association between loneliness and personality traits might be found in the way lonely individuals approach the world.

\section{Loneliness and the Self-Regulatory Focus}

Human beings are social beings and are hence equipped with a desire for social inclusion (Baumeister \& Leary, 1995; Cacioppo et al., 2015). If this desire is unfulfilled or threatened, most individuals react by reestablishing social ties and reaffiliating with others (Qualter et al., 2015) to end their state of loneliness. However, 
a substantial proportion of individuals seems to feel dispositionally more lonely than others, as has been shown by (a) studies employing latent class approaches (e.g., Vanhalst et al., 2013; Vanhalst et al., 2015) and (b) a meta-analysis on the rankorder stability of loneliness suggesting a high stability of inter-individual differences (Mund, Freuding, Möbius, Horn, \& Neyer, 2018). Individuals high in loneliness evince a specific pattern of information processing that is characterized by an increased vigilance towards cues of social exclusion and social threats (Cacioppo \& Hawkley, 2009; Hawkley \& Cacioppo, 2010, Spithoven, Bijttebier, \& Goossens, 2017). Paradoxically, this hypervigilance towards threatening cues does not initiate reaffilition in lonely individuals but rather serves to protect them from further harm (Spithoven et al., 2017).

Interacting with the world in such a defensive way with the primary goal of avoiding harm is characteristic for a self-regulatory focus geared towards prevention (Higgins, 1997, 1998). A self-regulatory focus geared towards promotion, in contrast, is accompanied by approach strategies (Higgins, 1997, 1998) such as reaffiliating with other individuals when feeling lonely (Qualter et al., 2015). While loneliness has been shown to be linked with a prevention focus, there is no consistent evidence for any association with a promotion focus (Spithoven et al., 2017).

Promotion and prevention focus have also been shown to be associated with at least some of the Big Five (Gorman et al., 2012). Specifically, meta-analytic findings suggest promotion focus to be positively related to extraversion and conscientiousness as well as negatively to neuroticism. Prevention focus, in turn, has been found to be positively associated with neuroticism and conscientiousness as well as negatively with extraversion (Gorman et al., 2012). Furthermore, several recent studies suggest that goals might influence the enactment of personality traits (McCabe \& Fleeson, 2012 , 2016). Based on these studies, it can be expected that a promotion focus, generally entailing approach strategies to achieve one's goals (Higgins, 1997, 1998), predicts, for instance, higher levels of extraversion (e.g, through more assertive behavior) and conscientiousness (e.g., through more goal-directed behavior) as well as lower levels of neuroticism (e.g., through less cautious, hesitant, or anxious behavior). Prevention focus, in contrast, generally entails avoidance strategies with the overarching goal of self-protection and harm avoidance (Higgins, 1997, 1998) and could thus be expected to be associated, for example, with higher levels of neuroticism and lower levels of extraversion by the enactment of more anxious and withdrawn behavior as well as less sociable and outgoing behavior, respectively in order to reduce the likelihood of being rejected. Taken together, self-regulatory focus, particularly geared towards prevention, qualifies as a candidate mechanism mediating the longitudinal effects of loneliness on personality traits.

\section{The Present Study}

The aims of the present study were to investigate the robustness and generalizability of the findings reported by Mund and Neyer (2016) by employing (a) a sample 
invoking different age groups, and (b) a direct measure of loneliness. Furthermore, we examined (c) the role of self-regulatory focus as a factor mediating the effects of loneliness on personality traits. Finally, we (d) explored age differences in the effects of loneliness on personality traits and the mediating role of self-regulatory focus.

Based on the study by Mund and Neyer (2016) and several cross-sectional as well as shorter-term longitudinal studies, we expected that loneliness would be positively associated with later levels of neuroticism as well as with the development of neuroticism. Concerning extraversion and conscientiousness, we expected loneliness to predict lower levels in these traits and to evince negative associations with their development. Although Mund and Neyer (2016) found no effects on agreeableness, we expected to find a negative association with loneliness in the present study given the consistency of previous research (Teppers et al., 2013 van der Aa et al., 2009; Vanhalst et al., 2013 Vanhalst et al., 2012). Because openness was not examined by Mund and Neyer (2016) and given the inconsistent findings in previous studies (Teppers et al., 2013, van der Aa et al., 2009, Vanhalst et al., 2013, Vanhalst et al., 2012), we did not derive specific hypothesis on its longitudinal association with loneliness. With regard to self-regulatory focus, building on prior research (Cacioppo \& Hawkley, 2009, Gorman et al., 2012 Hawkley \& Cacioppo, 2010. Spithoven et al., 2017), we expected prevention focus - but not promotion focus - to mediate the effects of loneliness on personality traits.

\section{Method}

\section{Participants}

The data were taken from the first six waves (W1 through W6 in the remainder) of the nationally representative German Family Panel (pairfam; Huinink et al., 2011). This ongoing study started in 2008 and assesses 12,402 participants in yearly homebased interviews. Pairfam sampled individuals from three different birth cohorts, born between 1991-1993 (Cohort 1), 1981-1983 (Cohort 2), and 1971-1973 (Cohort 3; see Supplemental Table S1 at https://osf.io/vtxhd/ for descriptives on age, sex, and education). A detailed overview over the sample composition, study design, and all instruments used in pairfam is available at http://www.pairfam.de/en/. Overall, the present sample included $51.40 \%$ women and the participants were, on average, $25.86(\mathrm{SD}=8.35)$ years old at $\mathrm{W} 1$.

\section{Measures}

Covariates. Following Mund and Neyer (2016), we included age, sex, and educational attainment as covariates in all analyses (see Supplemental Table S1 for descriptive statistics).

Personality. The Big Five personality traits were measured at W2 and W6 using the short version of the German Big Five Inventory (BFI-K; Rammstedt \& John, 2005). The BFI-K contains 21 items (five for openness, four for each of the 
other traits) answered on a 5-point Likert-type rating scale ranging from 1 (absolutely incorrect) to 5 (absolutely correct).

As indicator of scale reliability, we used coefficient $\omega$. Unlike coefficient $\alpha, \omega$ rests on assumptions that are more realistic in most research scenarios. Specifically, while coefficient $\omega$ requires $\tau$-congeneric scales that allow for items to differ from each other with regard to their (a) amount of true-score variance, (b) representativeness for the measured construct (i.e., item loadings), and (c) true-score means, coefficient $\alpha$ is only valid if scales are essentially $\tau$ - equivalent, that is, if all items contain the exact same amount of true-score variance and if the items are perfectly unidimensional. Thus, coefficient $\alpha$ is a special case of coefficient $\omega$ (Dunn, Baguley, \& Brunsden, 2014). At W2, coefficient $\omega$ varied between .57 (agreeableness) and .74 (extraversion); at W6, $\omega$ ranged from .61 (agreeableness) to .79 (extraversion (see Supplemental Table $\mathrm{S} 2$ for details).

Loneliness. Loneliness was assessed using a single item ("I feel lonely") answered on a 5-point Likert-type rating scale ranging from 1 (not at all) to 5 (absolutely). Loneliness was assessed at measurement waves 1, 4, and 5 but we only used the measure at W1. This direct single-item measure has proven valid (Pinquart \& Sörensen, 2001; Shiovitz-Ezra \& Ayalon, 2010) and reliable (Zhong, Chen, Tu, \& Conwell, 2016) in several previous studies.

Self-regulatory focus. Self-regulatory focus was assessed at W4 using two items measuring a promotion focus ("I think a lot about the realization of my ideals and dreams in the future"; "I work mostly toward realizing my hopes and wishes"; $\omega=.77$ ) and two items measuring a prevention focus ("I am often afraid that I cannot live up to demands and expectations"; "I have misgivings and fears about my future"; $\omega=.79$; see also Supplemental Table S2). All four items were answered on a 7-point Likert-type rating scale ranging from 1 (not at all) to 7 (absolutely).

\section{Analysis Model}

We used the same analytic models as Mund and Neyer (2016) with the exception that we used manifest variables throughout the analyses. As a result, all models were saturated. Specifically, as in Mund and Neyer (2016), the research questions of the present article were investigated with three analysis models. In the first model, we predicted the levels of the Big Five traits at W6 by the level of loneliness at W1 (see Figure 1a). In the second model, we predicted change in the Big Five traits between W2 and W6 by the levels of loneliness at W1. Change in personality traits was modeled by a two-wave first-order growth curve model (see Figure 1b). These two models are parallel to the models used by Mund and Neyer (2016). In the third model, we included prevention and promotion focus as parallel mediators of the association between loneliness at W1 and the levels of the Big Five traits at W6 (see Figure 2). All models were implemented as multivariate models, that is, they contained all predictors, outcomes, and covariates at once. To guard against suppressor effects and other undesired phenomena, we ran all models in their bivariate form as well (i.e, 


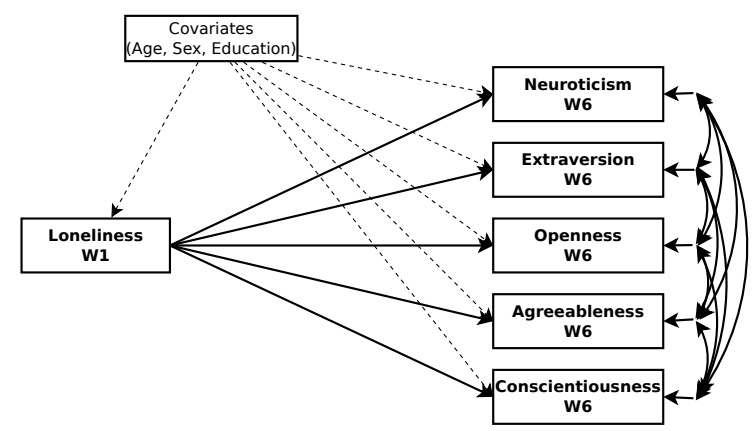

(a) Loneliness at $\mathrm{W} 1$ as predictor of personality levels at $\mathrm{W} 6$.

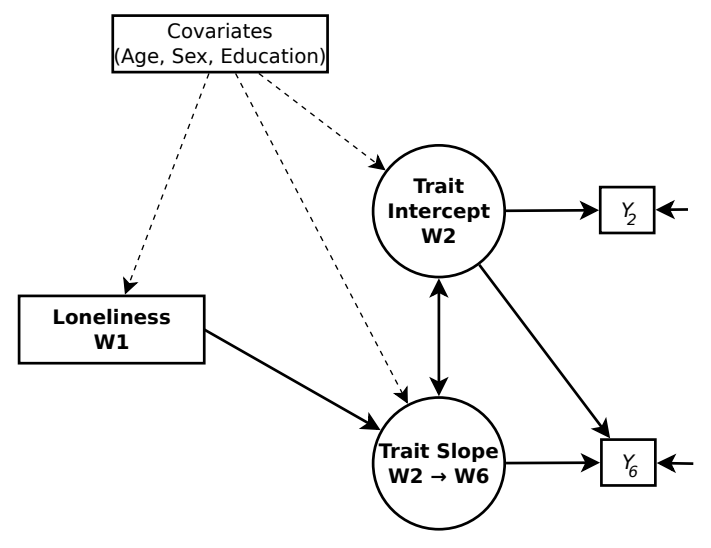

(b) Loneliness at W1 as predictor of personality change between $\mathrm{W} 2$ and $\mathrm{W} 6$.

Figure 1. Illustration of the models used for analysis. Note that (b) only shows a bivariate case; the focus models included change in all Big Five at once.

including the covariates but only one dependent variable). In a further set of control analyses, we ran all multivariate models without covariates.

To examine age-differential effects, we built on the multi-cohort design implemented in pairfam. To this end, we ran each model three times: In the first model, we estimated effects for the entire sample. In the second model, we estimated the effects for each cohort in a multi-group setup, thereby allowing the estimates to vary freely across cohorts. In the third model, finally, we constrained the effects obtained in the second model to be equal across cohorts. The second and the third model were then compared using a $\chi^{2}$-difference test to examine whether the constrained model

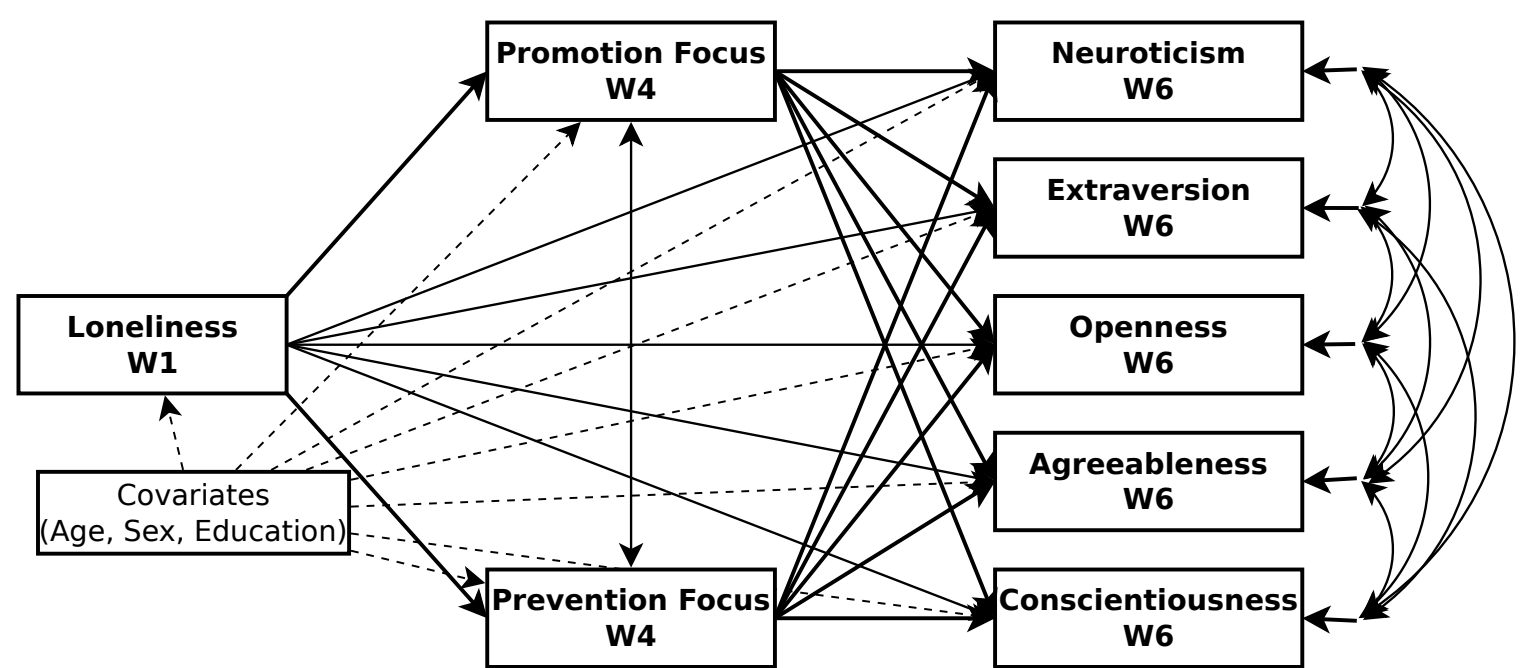

Figure 2. Mediation model to predict levels of personality traits at W6 by loneliness at W1. 
fitted the data worse than the unconstrained model, which would have indicated the presence of age-specific effects.

While the study by Mund and Neyer (2016) examined the association between loneliness and personality (development) across 15 years, the present study could only investigate these associations across four years. This difference might threaten the comparability of the results of the two studies. Thus, since the study by Mund and Neyer (2016) included more measurement occasions that were not used in their article, we reanalyzed their data for a four-year time interval to increase the comparability with the present study. Overall, the results for the four-year period were very similar to the originally reported estimates across 15 years, although the estimates for the four-year interval tended to be smaller than the original estimates (see Supplemental Table S3 and Supplemental Figure S1).

Since we had directed hypotheses with regard to the association between loneliness and personality traits, we conducted one-tailed tests of significance and constructed $90 \%$ confidence intervals (CI) around the parameter estimates, respectively. For the mediation analyses, we had no directed hypotheses and hence used two-tailed significance tests. Due to the large sample size and the high power of the present study, we only considered effects statistically significant with a $p$-value smaller than .01 and constructed $99 \%$ CI in the mediation analyses.

The significance of the indirect effects in the mediation analysis was tested via 5,000 draws of percentile bootstrap (MacKinnon, 2008). Furthermore, we calculated $\mathrm{P}_{\mathrm{M}}$ and $\mathrm{R}_{\mathrm{M}}$ as measures of effect size for the mediation. $\mathrm{P}_{\mathrm{M}}$ indicates the percentage of the direct effect that can be explained by the indirect effect. $R_{M}$ indicates the ratio of the indirect to the direct effect and hence signals whether the indirect effect is larger or smaller than the direct effect (MacKinnon, 2008). To be consistent across analyses, we used bootstrapping in all other models as well to determine standard errors. Missing data were treated with the Full Information Maximum Likelihood procedure (Enders, 2010). All analyses were conducted with the $\mathrm{R}$ package lavaan ( $\mathrm{R}$ Core Team, 2018; Rosseel, 2012); the full analysis syntax, complete model outputs, and all Supplemental Materials are accessible at https://osf.io/vtxhd/.

\section{Results}

Descriptive statistics for the study variables are summarized in Table 1 and Table 2 displays the zero-order correlations and rank-order stabilities of all study variables. Descriptive statistics for the covariates are summarized in Supplemental Table S1. 
Table 1

Descriptive Statistics for the Key Variables

\begin{tabular}{|c|c|c|c|c|c|c|c|}
\hline \multirow[b]{2}{*}{ Variable } & \multicolumn{2}{|c|}{ First Occasion } & \multicolumn{2}{|c|}{ Second Occasion } & \multicolumn{3}{|c|}{ Cohen's $d$} \\
\hline & $\mathrm{M}$ & SD & $\mathrm{M}$ & $\mathrm{SD}$ & $d$ & LB & UB \\
\hline Neuroticism & 2.67 & 0.80 & 2.73 & 0.80 & 0.08 & 0.04 & 0.12 \\
\hline Extraversion & 3.58 & 0.82 & 3.49 & 0.80 & -0.11 & -0.15 & -0.07 \\
\hline Openness & 3.68 & 0.69 & 3.60 & 0.68 & -0.12 & -0.16 & -0.08 \\
\hline Agreeableness & 3.26 & 0.73 & 3.28 & 0.70 & 0.03 & -0.01 & 0.07 \\
\hline Conscientiousness & 3.79 & 0.70 & 3.77 & 0.63 & -0.03 & -0.07 & 0.01 \\
\hline Loneliness & 1.65 & 1.01 & & & & & \\
\hline Promotion & 4.49 & 1.48 & & & & & \\
\hline Prevention & 3.38 & 1.60 & & & & & \\
\hline
\end{tabular}

Note. LB: lower bound of $99 \%$ confidence interval; UB: upper bound of $99 \%$ confidence interval. Numbers set in italics have $p>.01$. 
Zero-Order Correlations and Rank-Order Stabilities

\begin{tabular}{|c|c|c|c|c|c|c|c|c|c|c|c|c|c|c|c|c|c|c|c|c|c|c|c|c|}
\hline \multirow[b]{2}{*}{ Variable } & \multicolumn{3}{|c|}{1} & \multicolumn{3}{|c|}{2} & \multicolumn{3}{|c|}{3} & \multicolumn{3}{|c|}{4} & \multicolumn{3}{|c|}{5} & \multicolumn{3}{|c|}{6} & \multicolumn{3}{|c|}{7} & \multicolumn{3}{|c|}{8} \\
\hline & $r$ & LB & UB & $r$ & LB & UB & $r$ & LB & UB & $r$ & LB & UB & $r$ & LB & UB & $r$ & LB & UB & $r$ & LB & UB & & LB & UB \\
\hline 1 Neuroticism (W2) & .55 & .52 & .57 & & & & & & & & & & & & & & & & & & & & & \\
\hline 2 Extraversion (W2) & -.28 & -.30 & -.25 & .65 & .63 & 67 & & & & & & & & & & & & & & & & & & \\
\hline 3 Openness (W2) & .01 & -.02 & .04 & .25 & .22 & .28 & .61 & .59 & .63 & & & & & & & & & & & & & & & \\
\hline 4 Agreeableness (W2) & -.18 & -.21 & -.15 & .11 & .08 & .14 & .02 & -.01 & .05 & .48 & .45 & .51 & & & & & & & & & & & & \\
\hline 5 Conscientiousness (W2) & -.18 & -.21 & -.15 & .20 & .17 & .23 & .17 & .14 & .20 & .16 & .13 & .19 & .55 & .52 & .57 & & & & & & & & & \\
\hline 6 Loneliness (W1) & .24 & .21 & .27 & -.17 & -.20 & -.14 & .03 & .00 & .06 & -.07 & -.10 & -.04 & -.10 & -.08 & -.02 & & & & & & & & & \\
\hline 7 Promotion (W4) & .01 & -.02 & .04 & .11 & .08 & .14 & .17 & .14 & .20 & -.07 & -.10 & -.04 & .02 & -.01 & .05 & .01 & -.02 & .04 & & & & & & \\
\hline 8 Prevention (W4) & .39 & .36 & .42 & -.12 & -.15 & -.09 & .06 & .03 & .09 & -.14 & -.17 & -.11 & -.22 & -.25 & -.19 & .19 & .16 & .22 & .21 & .18 & .24 & & & \\
\hline
\end{tabular}
$\begin{array}{llllllllllllllll} & 8\end{array}$

Note. LB: lower bound of $99 \%$ confidence interval; 0 B: upper bound of $99 \%$ confidence interval.
the variable's rank-order stability across 4 years (only personality traits were measured twice). 


\section{Loneliness and Personality Levels}

As shown in Table 3, loneliness at W1 was a statistically significant predictor of all traits except openness. Loneliness was positively associated with neuroticism and negatively with extraversion, agreeableness, and conscientiousness. These effects did not differ between cohorts, as indicated by a nonsignificant $\chi^{2}$-difference test $\left(\Delta d f=10, \Delta \chi^{2}=6.06, p=.8106\right)$. Furthermore, the results did neither differ between bivariate and multivariate models (see Table 3) nor between models with versus without covariates (see Supplemental Figure S2).

Table 3

Prediction of Personality Traits at W6 by Loneliness at W1

\begin{tabular}{|c|c|c|c|c|c|c|c|c|}
\hline \multirow[b]{2}{*}{ Criterion } & \multicolumn{4}{|c|}{ Bivariate } & \multicolumn{4}{|c|}{ Multivariate } \\
\hline & $b$ & LB & UB & $p$ & $b$ & LB & UB & $p$ \\
\hline Neuroticism & 0.168 & 0.150 & 0.185 & $<.001$ & 0.168 & 0.149 & 0.186 & $<.001$ \\
\hline Extraversion & -0.111 & -0.130 & -0.093 & $<.001$ & -0.111 & -0.129 & -0.093 & $<.001$ \\
\hline Openness & 0.012 & -0.003 & 0.027 & .100 & 0.011 & -0.004 & 0.027 & .112 \\
\hline Agreeableness & -0.067 & -0.082 & -0.052 & $<.001$ & -0.067 & -0.082 & -0.052 & $<.001$ \\
\hline Conscientiousness & -0.075 & -0.089 & -0.061 & $<.001$ & -0.075 & -0.090 & -0.060 & $<.001$ \\
\hline
\end{tabular}

Note. b: unstandardized regression weight; LB: lower bound of 90\% confidence interval; UB: upper bound of $90 \%$ confidence interval; Statistical tests are one-tailed. All models included age, sex, and education as covariates.

Overall, these results align with the findings reported by Mund and Neyer (2016): As depicted in Figure 3, the unstandardized regression coefficients obtained in the present study and those reported by Mund and Neyer $(2016)$ overlap in the cases of extraversion and agreeableness. For neuroticism and conscientiousness, the confidence intervals did not overlap, but the effects ran in the same direction. In addition to the study by Mund and Neyer (2016), we also found loneliness to be negatively associated with agreeableness.

\section{Loneliness and Personality Development}

As displayed in Table 4 and in Figure 4 , loneliness at W1 had a statistically significant effect on the development of neuroticism and extraversion over four years between W2 and W6. However, given that neuroticism was found to increase in the present sample (see Table 1), the negative effect of loneliness indicates that higher levels of loneliness at baseline predicted smaller increases in neuroticism. Similarly, given the average decrease in extraversion in the sample, the positive effect of loneliness suggests that higher loneliness at W1 predicted less steep decreases in this trait. It should be noted, though, that these effects were very small. As before, the effects of loneliness on personality development did neither differ between cohorts $\left(\Delta d f=10, \Delta \chi^{2}=8.10, p=.6191\right)$ nor between bivariate and multivariate analyses (see Table 4), and did not depend on whether covariates were included or not (see Supplemental Figure S2). 


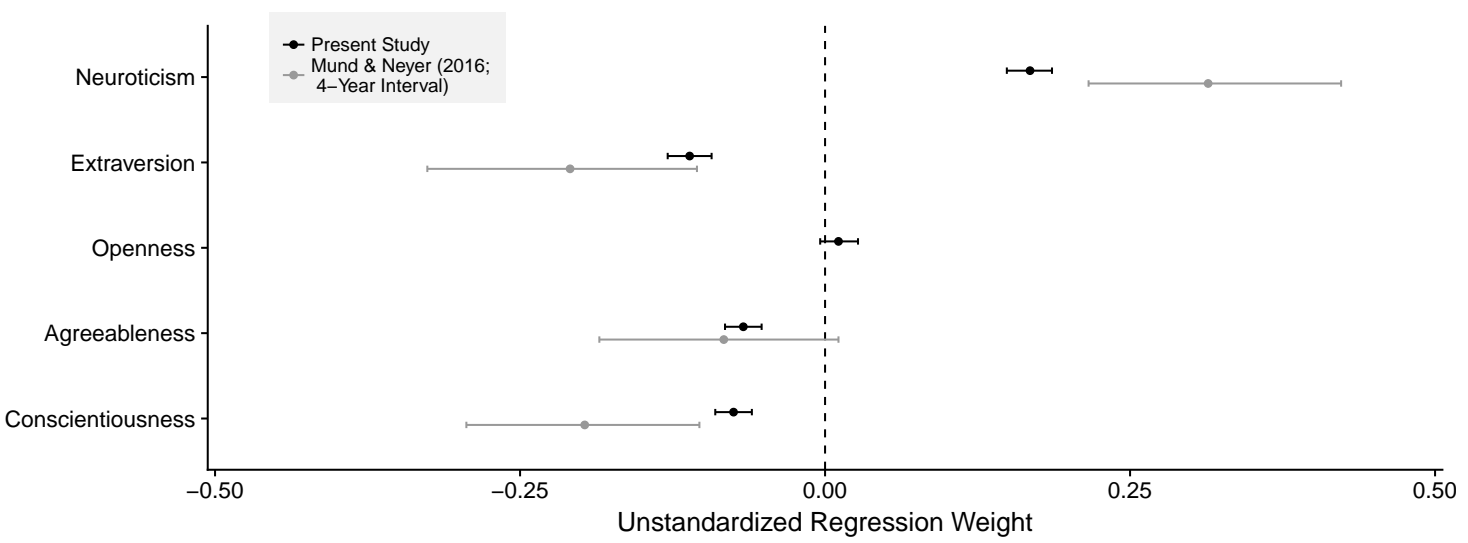

Figure 3. Comparison of unstandardized regression weights for the prediction of personality levels in the study by Mund and Neyer (2016, gray dots) and the present study (black dots). Dashed vertical line denotes zero. Horizontal lines depict confidence intervals (95\% for Mund and Neyer (2016) and 90\% for the present study).

In sum, contrary to Mund and Neyer (2016), we found no evidence of loneliness substantially predicting personality trait development over a period of four years. However, it should be noted that, by indicating no mean-level change, even the results of the univariate analyses of the present study (see also Table 1) differed from metaanalytic findings on mean-level development of the Big Five (Roberts, Walton, \& Viechtbauer, 2006).

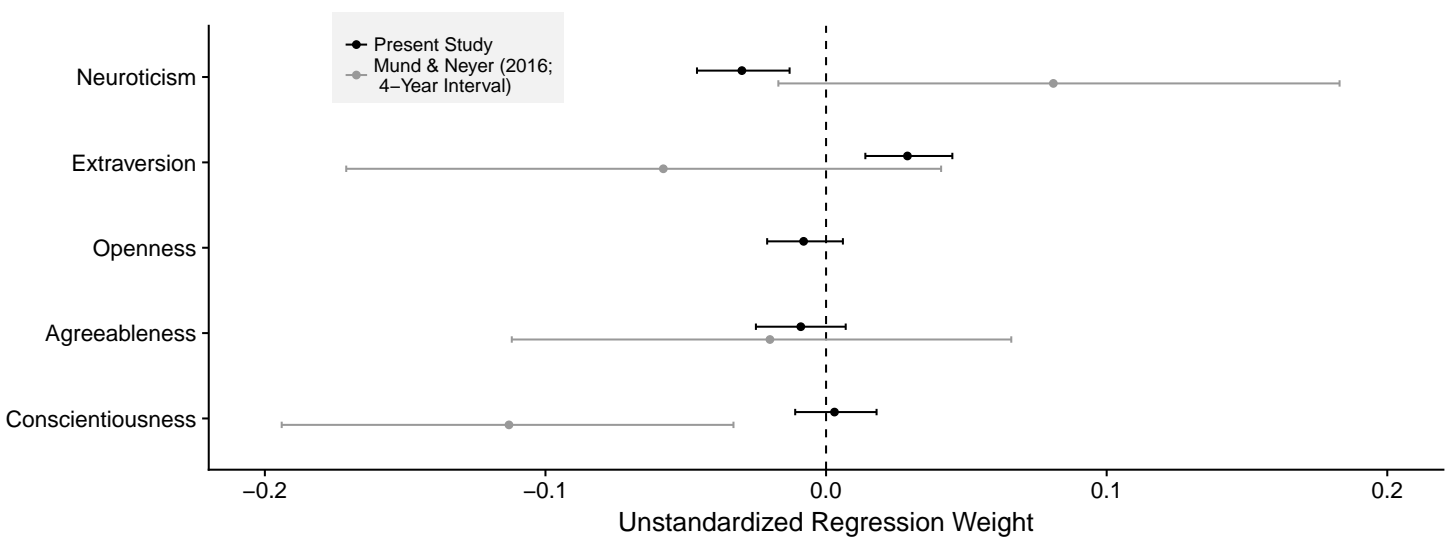

Figure 4. Comparison of unstandardized regression weights for the prediction of personality development in the study by Mund and Neyer (2016, gray dots) and the present study (black dots). Dashed vertical line denotes zero. Horizontal lines depict confidence intervals (95\% for Mund and Neyer (2016) and 90\% for the present study). 


\section{The Role of Self-Regulatory Focus}

Table 5 displays the estimates of the specific indirect effects of the mediation analyses (for $a$ - and $b$-paths, see Supplemental Table S4). As expected, due to nonsignificant $a$-paths, no effects were found for promotion focus. Prevention focus, however, turned out as a statistically significant mediator of the effects of loneliness on neuroticism, extraversion, agreeableness, and conscientiousness. In terms of effect sizes (MacKinnon, 2008), prevention focus explained between 23.2 and $39.0 \%$ of the direct effect of loneliness on the Big Five traits $\left(\mathrm{P}_{\mathrm{M}}\right.$ in Table 5). The indirect effects were, overall, smaller than the direct effects $\left(\mathrm{R}_{\mathrm{M}}\right.$ in Table 5). 
Table 4

Prediction of Personality Development Between W2 and W6 by Loneliness at W1

\begin{tabular}{|c|c|c|c|c|c|c|c|c|}
\hline \multirow[b]{2}{*}{ Criterion } & \multicolumn{4}{|c|}{ Bivariate } & \multicolumn{4}{|c|}{ Multivariate } \\
\hline & $b$ & LB & UB & $p$ & $b$ & LB & UB & $p$ \\
\hline Neuroticism & -0.029 & -0.046 & -0.013 & .002 & -0.030 & -0.046 & -0.013 & .002 \\
\hline Extraversion & 0.029 & 0.013 & 0.045 & .001 & 0.029 & 0.014 & 0.045 & .001 \\
\hline Openness & -0.008 & -0.022 & 0.006 & .171 & -0.008 & -0.021 & 0.006 & .170 \\
\hline Agreeableness & -0.009 & -0.025 & 0.007 & .181 & -0.009 & -0.025 & 0.007 & .187 \\
\hline Conscientiousness & 0.003 & -0.012 & 0.016 & .381 & 0.003 & -0.011 & 0.018 & .346 \\
\hline
\end{tabular}

Note. $b$ : unstandardized regression weight; LB: lower bound of $90 \%$ confidence interval; UB: upper bound of $90 \%$ confidence interval; Statistical tests are one-tailed. All models included age, sex, and education as covariates. 
Table 5

Specific Indirect Effects of the Mediation Analyses

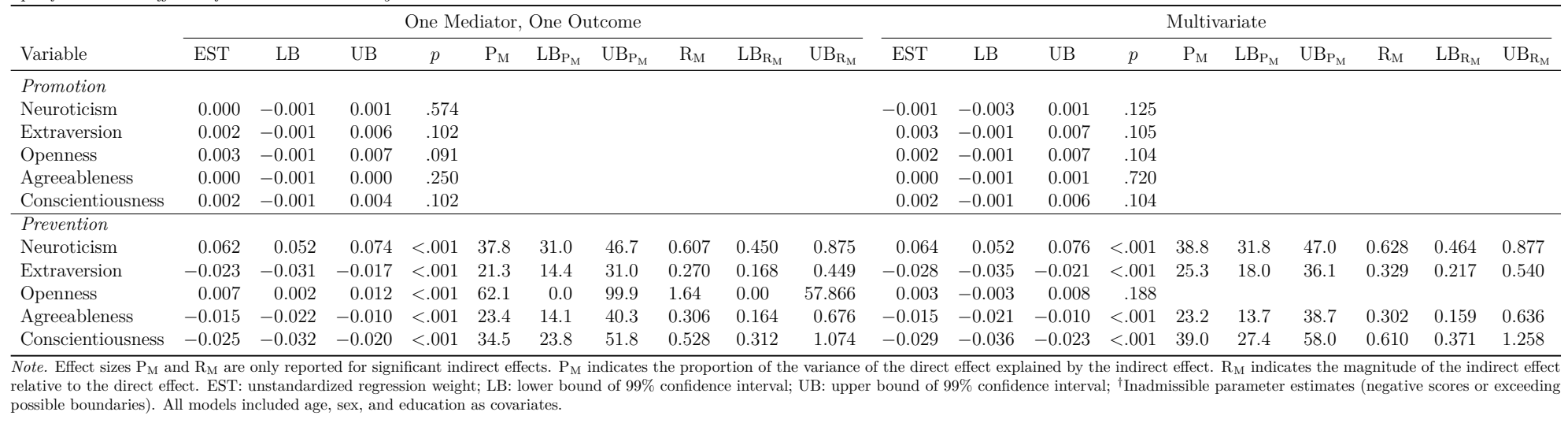


As indicated by a significant $\chi^{2}$-difference test $\left(\Delta d f=34, \Delta \chi^{2}=74.57, p<\right.$ .001 ), the results of the mediation models differed between cohorts. Further inspection revealed that the indirect effects of prevention focus for all traits but openness were stronger in the oldest cohort than in the youngest cohort. The middle cohort did not differ from either the youngest or the oldest cohort. Concerning openness, the indirect effect of prevention focus was stronger in the youngest cohort than in the two other cohorts; in fact, this effect was statistically significant in the youngest cohort only.

The results did not differ between the multivariate analysis and the models invoking only one mediator and one dependent variable with one exception that the effect of loneliness on later levels of openness was mediated by prevention focus in the latter analysis. This effect, however, disappeared when we controlled for the other Big Five traits and promotion focus (see Table 5). Finally, the results did not differ between models with and without covariates (see Supplemental Figure S3).

\section{Discussion}

Loneliness occurs when individuals perceive a discrepancy between the desired and the actually experienced quality and quantity of social relationships (de Jong Gierveld, 1998 Ernst \& Cacioppo, 1999 Hawkley \& Cacioppo, 2010). In a large body of research, loneliness has been shown to be associated with a wide variety of health-related outcomes (for reviews, see Ernst \& Cacioppo, 1999, Hawkley \& Cacioppo, 2010). A recent study by Mund and Neyer (2016) has extended this literature by showing that loneliness is also longitudinally linked with less socially desirable levels of personality traits and to a less beneficial development of these traits. However, their study suffered from several limitations and remained silent about the mechanisms linking loneliness and personality traits. In the present study, we extended the findings by Mund and Neyer (2016) by investigating the robustness of the effects of loneliness on personality traits and mechanisms mediating these effects.

\section{Loneliness Effects on Personality}

Mund and Neyer (2016) were the first to demonstrate longitudinal effects of loneliness on personality traits and their development across adulthood. By using data from a representative panel study, we found the effects of global loneliness on later levels of personality traits to be robust. Furthermore, the effects of loneliness appeared to be independent of the age groups assessed. The findings of the present study align well with prior findings from cross-sectional and shorter-term longitudinal studies (Hensley et al., 2012 Saklofske \& Yackulic, 1989 Stokes, 1985, Teppers et al., 2013 van der Aa et al., 2009; Vanhalst et al., 2013 Vanhalst et al., 2012) by demonstrating that loneliness is positively associated with neuroticism and negatively with extraversion and agreeableness. Furthermore, the present study adds to the ambiguous findings on the association between loneliness and both openness and 
conscientiousness. With regard to openness, the present study suggests that loneliness is unrelated to this trait, thereby supporting previous finding (Teppers et al., 2013; Vanhalst et al., 2013). Similarly, as van der Aa et al. (2009) and Mund and Neyer (2016), we found a negative association between loneliness and conscientiousness.

Following the rationale of the kindling effect (Kendler et al., 1993; Monroe \& Harkness, 2005), loneliness might leave scars in individuals' personality. These vulnerabilities might be brought about by withdrawing from interaction partners or otherwise disengaging from close relationships in order to avoid (further) rejection (for a review, see Spithoven et al., 2017). As a consequence, lonely individuals might lack the opportunity to maintain close and stable relationships that have been shown to be essential for a socially desirable pattern of personality development (Mund \& Neyer, 2014 Neyer \& Asendorpf, 2001). Indeed, individuals high in loneliness seem to generally report more negative affect after interactions with others (Hawkley et al., 2003 Queen, Stawski, Ryan, \& Smith, 2014 van Roekel, Ha, Scholte, Engels, \& Verhagen, 2016), which might initiate a vicious circle of negative interactions (Cacioppo \& Hawkley, 2009, Spithoven et al., 2017; see also McNulty, 2008) that in the long run might lead to the pattern of personality traits observed in the present study.

Contrary to Mund and Neyer (2016), we found no substantial effects of loneliness on the development of the Big Five. In addition, the patterns of personality development observed in the present study diverged from prior research indicating average decreases in neuroticism as well as increases in agreeableness and conscientiousness across adulthood (Roberts et al., 2006). It can be speculated that a reason for this result might lie in the assessment of the Big Five traits in the pairfam sample: The BFI-K is a short scale to assess broad personality traits, thereby inevitably favoring bandwidth over fidelity (e.g., Hogan \& Roberts, 1996). Although reliably capturing individual levels of the Big Five, the BFI-K might not have assessed the facets of the traits that drive personality development in the first place or sampled items from facets that change in different directions (Mund \& Neyer, 2014; Soto \& John, 2012), leading to the observation of no mean-level change. In line with this reasoning, other studies that have employed similarly bandwidth-focused measures (e.g., Lucas \& Donnellan, 2011; Milojev \& Sibley, 2017; Specht, Egloff, \& Schmukle, 2011: Wortman, Lucas, \& Donnellan, 2012) also reported patterns of personality development that diverge from the meta-analytic findings by Roberts et al. (2006).

The effects of loneliness on later levels of the Big Five traits were smaller than in the study by Mund and Neyer (2016). This difference in magnitude might be due to the different ways loneliness was measured in the two studies: While Mund and Neyer (2016) used an indirect measure of loneliness, the present study employed a direct measure which required participants to label themselves as lonely. Similar differences between direct and indirect measures with regard to the magnitude of effects have been reported for sex differences in the prevalence of loneliness (Borys \& Perlman, 1985 Pinquart \& Sörensen, 2001) and other demographic correlates (Shiovitz-Ezra \& Ayalon, 2012, Victor et al., 2005). These differences in effect size notwithstanding, the 
finding that loneliness is longitudinally linked with personality traits irrespective of the measure is a strong case for the robustness and generalizability of this association. Thus, the present study can be considered a conceptual replication of the study by Mund and Neyer (2016), suggesting that loneliness effects on personality traits can be expected to be found in a wide variety of circumstances from late adolescence to early midlife.

\section{The Role of Self-Regulatory Focus}

Prior research has shown that individuals feeling act more defensively and try to avoid negative outcomes, particularly in the social domain (for reviews, see Cacioppo \& Hawkley, 2009 Spithoven et al., 2017). The present study has demonstrated that this prevention focus (Higgins, 1997, 1998) plays a role in shaping the personality of individuals feeling lonely. Specifically, across all age groups examined, a self-regulatory focus geared towards the prevention of negative outcomes was found to mediate the longitudinal linkages between loneliness and all traits but openness. In addition to maintaining and chronifying loneliness (Vanhalst et al., 2015), such a prevention focus thus appears to spill over to influence broader personality traits. Individuals dispositionally employing a prevention focus are rather passive and avoidant (Higgins, 1997, 1998). In social situations, these patterns of interaction might prevent the creation and maintenance of relationships as close and intimate as required to influence personality and its development (Mund \& Neyer, in press). In this way, the negative affective state associated with loneliness (Cacioppo \& Hawkley, 2009, Perlman \& Peplau, 1981; Spithoven et al., 2017) cannot be resolved and might further lead to (maladaptive) coping behaviors (e.g., smoking, excessive alcohol consumption; Åkerlind \& Hörnquist, 1992; DeWall \& Pond, 2011; Hawkley et al., 2009; Lauder et al., 2006 Shankar et al., 2011).

It should also be noted that loneliness was not associated with a promotion focus in the present study. This finding, which is in line with prior research (for reviews, see Qualter et al., 2015; Spithoven et al., 2017), indicates that lonely individuals are not unable to pursue their goals in a proactive way. However, while they appear to employ prevention-focused strategies dispositionally, the endorsement of promotionoriented strategies might depend more on contextual features for individuals feeling lonely.

\section{Limitations}

The present study has limitations. First, with self-regulatory focus, we concentrated on a broad mechanism connecting loneliness and personality traits. Thus, the identification of more specific processes such as concrete patterns of social interaction must remain subject to future research tailored to identify such micro-processes. As more and finer-grained mediating variables are known, it might be possible to conduct more complex analyses (e.g., sequential mediation) that might allow future research 
to establish a causal chain describing how loneliness effects on personality are brought about.

Second, loneliness and the Big Five have not been measured at the same measurement occasion in the present study. As a consequence, we could not fully control for the initial correlations between loneliness and the Big Five and thus cannot rule out that the observed loneliness effects might at least partly due to a stable correlation between the constructs over time. However, the results of the present study are very similar to those obtained by Mund and Neyer (2016), who took into account these initial correlations.

Third, the present study investigated individuals isolated from their social contexts. Future research might benefit from investigating patterns of interactions between individuals scoring high on loneliness and their peers (for pioneering studies, see Queen et al., 2014, van Roekel et al., 2016). This might enable researchers to understand how loneliness and the associated prevention focus manifest and interact in real-life contexts.

Finally, in the present study we did not examine the dynamic longitudinal interplay between loneliness and the Big Five traits. Future studies with multiple measurement waves of loneliness, personality traits, and mechanisms possibly mediating the effects between both might further unravel reciprocal patterns of loneliness and personality across adulthood.

\section{Conclusion}

In the present study, we demonstrated loneliness effects on later levels personality traits in a representative German sample. Specifically, we found these effects to be robust and generalizable from late adolescence to early midlife. Furthermore, these effects were partially mediated by a self-regulatory focus geared to the prevention of negative outcomes and thus by differences in how individuals feeling lonely dispositionally approach the world. 


\section{Acknowledgements}

In this article, we used data from the German Family Panel pairfam, coordinated by Josef Brüderl, Karsten Hank, Johannes Huinink, Bernhard Nauck, Franz J. Neyer, and Sabine Walper. Pairfam is funded as long-term project by the German Research Foundation (DFG; Deutsche Forschungsgemeinschaft).

\section{Declaration of Conflicting Interests}

The author(s) declared no potential conflicts of interest with respect to the research, authorship, and/or publication of this article.

\section{Funding}

Preparation of this manuscript was supported by grant DRM/2017-06 awarded to Marcus Mund from the Friedrich-Schiller-Universität Jena and by German Research Foundation Grant NE 633/10-3 awarded to Franz J. Neyer.

\section{References}

Åkerlind, I. \& Hörnquist, J. O. (1992). Loneliness and alcohol abuse: A review of evidences of an interplay. Social Science $\mathscr{E}$ Medicine, 34, 405-414. doi:10.1016/ 0277-9536(92)90300-F

Baumeister, R. F. \& Leary, M. R. (1995). The need to belong: Desire for interpersonal attachment as a fundamental human motivation. Psychological Bulletin, 117, 497-529. doi:10.1037/0033-2909.117.3.497

Bogg, T. \& Roberts, B. W. (2004). Conscientiousness and health-related behaviors: A meta-analysis of the leading behavioral contributors to mortality. Psychological Bulletin, 130, 887-919. doi:10.1037/0033-2909.130.6.887

Borys, S. \& Perlman, D. (1985). Gender differences in loneliness. Personality and Social Psychology Bulletin, 11, 63-74. doi:10.1177/0146167285111006

Cacioppo, J. T., Cacioppo, S., Cole, S. W., Capitanio, J. P., Goossens, L., \& Boomsma, D. I. (2015). Loneliness across phylogeny and a call for comparative studies and animal models. Perspectives on Psychological Science, 10, 202212. doi:10.1177/1745691614564876

Cacioppo, J. T. \& Hawkley, L. C. (2009). Perceived social isolation and cognition. Trends in Cognitive Sciences, 13, 447-454. doi:10.1016/j.tics.2009.06.005

Cacioppo, J. T., Hawkley, L. C., \& Thisted, R. A. (2010). Perceived social isolation makes me sad: 5-year cross-lagged analyses of loneliness and depressive symptomatology in the Chicago Health, Aging, and Social Relations Study. Psychology and Aging, 25, 453-463. doi:10.1037/a0017216

Cacioppo, J. T., Hughes, M. E., Waite, L. J., Hawkley, L. C., \& Thisted, R. A. (2006). Loneliness as a specific risk factor for depressive symptoms: Cross-sectional and longitudinal analyses. Psychology and Aging, 21, 140-151. doi:10.1037/08827974.21.1.140 
de Jong Gierveld, J. (1998). A review of loneliness: Concept and definitions, determinants and consequences. Reviews in Clinical Gerontology, 8, 73-80. doi:10. 1017/S0959259898008090

DeWall, C. N. \& Pond, R. S. (2011). Loneliness and smoking: The costs of the desire to reconnect. Self and Identity, 10, 375-385. doi:10.1080/15298868.2010.524404

Dunn, T. J., Baguley, T., \& Brunsden, V. (2014). From alpha to omega: A practical solution to the pervasive problem of internal consistency estimation. British Journal of Psychology, 105, 399-412. doi:10.1111/bjop.12046

Enders, C. K. (2010). Applied missing data analysis. New York: Guilford Press.

Ernst, J. M. \& Cacioppo, J. T. (1999). Lonely hearts: Psychological perspectives on loneliness. Applied and Preventive Psychology, 8, 1-22. doi:10.1016/S09621849(99)80008-0

Gorman, C. A., Meriac, J. P., Overstreet, B. L., Apodaca, S., McIntyre, A. L., Park, P., \& Godbey, J. N. (2012). A meta-analysis of the regulatory focus nomological network: Work-related antecedents and consequences. Journal of Vocational Behavior, 80, 160-172. doi:10.1016/j.jvb.2011.07.005

Hakulinen, C., Elovainio, M., Batty, G. D., Virtanen, M., Kivimäki, M., \& Jokela, M. (2015). Personality and alcohol consumption: Pooled analysis of 72,949 adults from eight cohort studies. Drug and Alcohol Dependence, 151, 110-114. doi:10. 1016/j.drugalcdep.2015.03.008

Hakulinen, C., Hintsanen, M., Munafó, M. R., Virtanen, M., Kivimäki, M., Batty, G. D., \& Jokela, M. (2015). Personality and smoking: Individual-participant meta-analysis of nine cohort studies. Addiction, 110, 1844-1852. doi:10.1111/ add.13079

Hawkley, L. C., Burleson, M. H., Berntson, G. G., \& Cacioppo, J. T. (2003). Loneliness in everyday life: Cardiovascular activity, psychosocial context, and health behaviors. Journal of Personality and Social Psychology, 85, 105-120. doi:10. 1037/0022-3514.85.1.105

Hawkley, L. C. \& Cacioppo, J. T. (2010). Loneliness matters: A theoretical and empirical review of consequences and mechanisms. Annals of Behavioral Medicine, 40, 218-227. doi:10.1007/s12160-010-9210-8

Hawkley, L. C., Thisted, R. A., \& Cacioppo, J. T. (2009). Loneliness predicts reduced physical activity: Cross-sectional \& longitudinal analyses. Health Psychology, 28, 354-363. doi:10.1037/a0014400

Hawkley, L. C., Thisted, R. A., Masi, C. M., \& Cacioppo, J. T. (2010). Loneliness predicts increased blood pressure: 5-year cross-lagged analyses in middle-aged and older adults. Psychology and Aging, 25, 132-141. doi:10.1037/a0017805

Hensley, B., Martin, P., Margrett, J. A., MacDonald, M., Siegler, I. C., \& Poon, L. W. (2012). Life events and personality predicting loneliness among centenarians: Findings from the Georgia Centenarian Study. Journal of Psychology, 146, 173188. doi:10.1080/00223980.2011.613874 
Higgins, E. T. (1997). Beyond pleasure and pain. American Psychologist, 52, 12801300. doi:10.1037/0003-066X.52.12.1280

Higgins, E. T. (1998). Promotion and prevention: Regulatory focus as a motivational principle. In M. P. Zanna (Ed.), Advances in experimental social psychology (Vol. 30, pp. 1-46). San Diego: Academic Press.

Hogan, J. \& Roberts, B. W. (1996). Issues and non-issues in the fidelity-bandwidth trade-off. Journal of Organizational Behavior, 17, 627-637. Retrieved from http: //www.jstor.org/stable/2488580

Huinink, J., Brüderl, J., Nauck, B., Walper, S., Castiglioni, L., \& Feldhaus, M. (2011). Panel analysis of intimate relationships and family dynamics (pairfam): Conceptual framework and design. Zeitschrift für Familienforschung, 23, 77-101.

Kendler, K. S., Neale, M. C., Kessler, R. C., Heath, A. C., \& Eaves, L. J. (1993). A longitudinal twin study of personality and major depression in women. Archives of General Psychiatry, 50, 853-862. doi:10.1001/archpsyc.1993.01820230023002

Lauder, W., Mummery, K., Jones, M., \& Caperchione, C. (2006). A comparison of health behaviours in lonely and non-lonely populations. Psychologiy, Health, \& Medicine, 11, 233-245. doi:10.1080/13548500500266607

Lucas, R. E. \& Donnellan, M. B. (2011). Personality development across the life span: Longitudinal analyses with a national sample from Germany. Journal of Personality and Social Psychology, 101, 847-861. doi:10.1037/a0024298

MacKinnon, D. P. (2008). Introduction to statistical mediation analysis. New York: Lawrence Erlbaum.

McCabe, K. O. \& Fleeson, W. (2012). What is extraversion for? Integrating trait and motivational perspectives and identifying the purpose of extraversion. Psychological Science, 23, 1498-1505. doi:10.1177/0956797612444904

McCabe, K. O. \& Fleeson, W. (2016). Are traits useful? Explaining trait manifestations as tools in the pursuit of goals. Journal of Personality and Social Psychology, 110, 287-301. doi:10.1037/a0039490

McNulty, J. K. (2008). Neuroticism and interpersonal negativity: The independent contributions of perceptions and behaviors. Personality and Social Psychology Bulletin, 34, 1439-1450. doi:10.1177/0146167208322558

Milojev, P. \& Sibley, C. G. (2017). Normative personality trait development in adulthood: A 6-year cohort-sequential growth model. Journal of Personality and Social Psychology, 112, 510-526. doi:10.1037/pspp0000121

Monroe, S. M. \& Harkness, K. L. (2005). Life stress, the "kindling" hypothesis, and the recurrence of depression: Considerations from a life stress perspective. Psychological Review, 112, 417-445. doi:10.1037/0033-295X.112.2.417

Mund, M., Freuding, M. M., Möbius, K., Horn, N., \& Neyer, F. J. (2018). All by myself: A meta-analysis on the stability and change of loneliness across the lifespan. Manuscript submitted for publication. 
Mund, M. \& Neyer, F. J. (2014). Treating personality-relationship transactions with respect: Narrow facets, advanced models, and extended time frames. Journal of Personality and Social Psychology, 107, 352-368. doi:10.1037/a0036719

Mund, M. \& Neyer, F. J. (2016). The winding paths of the lonesome cowboy: Evidence for mutual influences between personality, subjective health, and loneliness. Journal of Personality, 84, 646-657. doi:10.1111/jopy.12188

Mund, M. \& Neyer, F. J. (in press). Wild horses dressed like unicorns: Relationship effects on personality. In J. F. Rauthmann (Ed.), The handbook of personality dynamics and processes. San Diego: Elsevier.

Neyer, F. J. \& Asendorpf, J. B. (2001). Personality-relationship transaction in young adulthood. Journal of Personality and Social Psychology, 81, 1190-1204. doi:10. 1037//0022-3514.81.6.1190

Perlman, D. \& Peplau, L. A. (1981). Toward a social psychology of loneliness. In N. Duck \& R. Gilmour (Eds.), Personal relationships in disorder (pp. 31-56). London: Academic Press.

Pinquart, M. \& Sörensen, S. (2001). Influences on loneliness in older adults: A metaanalysis. Basic and Applied Social Psychology, 23, 245-266.

Qualter, P., Brown, S. L., Munn, P., \& Rotenberg, K. J. (2010). Childhood loneliness as a predictor of adolescent depressive symptoms: An 8-year longitudinal study. European Child and Adolescent Psychiatry, 19, 493-501. doi:10.1007/s00787009-0059-y

Qualter, P., Vanhalst, J., Harris, R., van Roekel, E., Lodder, G., Bangee, M., .. Verhagen, M. (2015). Loneliness across the life span. Perspectives on Psychological Science, 10, 250-264. doi:10.1177/1745691615568999

Queen, T. L., Stawski, R. S., Ryan, L. H., \& Smith, J. (2014). Loneliness in a day: Activity engagement, time alone, and experienced emotions. Psychology and Aging, 29, 297-305. doi:10.1037/a0036889

R Core Team. (2018). R: A language and environment for statistical computing. Vienna: R Foundation for Statistical Computing. Retrieved from http://www.rproject.org

Rammstedt, B. \& John, O. P. (2005). Kurzversion des Big Five Inventory (BFI-K): Entwicklung und Validierung eines ökonomischen Inventars zur Erfassung der fünf Faktoren der Persönlichkeit [Short version of the Big Five Inventory (BFI$\mathrm{K})$ : Development and validation of an economic inventory for the assessment of the five factors of personality]. Diagnostica, 51, 195-206. doi:10.1026/00121924.51.4.195

Roberts, B. W., Walton, K. E., \& Viechtbauer, W. (2006). Patterns of mean-level change in personality traits across the life course: A meta-analysis of longitudinal studies. Psychological Bulletin, 132, 1-25. doi:10.1037/0033-2909.132.1.1

Rosseel, Y. (2012). lavaan: An R package for structural equation modeling. Journal of Statistical Software, 48, 1-36. Retrieved from http://www.jstatsoft.org/v48/ i02/paper 
Rotenberg, K. J. (1998). Stigmatization of transitions in loneliness. Journal of Social and Personal Relationships, 15, 565-576. doi:10.1177/0265407598154008

Rotenberg, K. J. \& Kmill, J. (1992). Perceptions of lonely and non-lonely persons as a function of individual differences in loneliness. Journal of Social and Personal Relationships, 9, 325-330. doi:10.1177/0265407592092009

Russell, D., Cutrona, C. E., Rose, J., \& Yurko, K. (1984). Social and emotional loneliness: An examination of Weiss's typology of loneliness. Journal of Personality and Social Psychology, 46, 1313-1321. doi:10.1037/0022-3514.46.6.1313

Saklofske, D. H. \& Yackulic, R. A. (1989). Personality predictors of loneliness. Personality and Individual Differences, 10, 467-472. doi:10.1016/0191-8869(89)900111

Shankar, A., McMunn, A., Banks, J., \& Steptoe, A. (2011). Loneliness, social isolation, and behavioral and biological health indicators in older adults. Health Psychology, 30, 377-385. doi:10.1037/a0022826

Shiovitz-Ezra, S. \& Ayalon, L. (2010). Situational versus chronic loneliness as risk factors for all-cause mortality. International Psychogeriatrics, 22, 455-462. doi:10. 1017/S1041610209991426

Shiovitz-Ezra, S. \& Ayalon, L. (2012). Use of direct versus indirect approaches to measure loneliness in later life. Research on Aging, 34, 572-591. doi:10.1177/ 0164027511423258

Soto, C. J. \& John, O. P. (2012). Development of Big Five domains and facets in adulthood: Mean-level age trends and broadly versus narrowly acting mechanisms. Journal of Personality, 80, 881-914. doi:10.1111/j.1467-6494.2011.00752.x

Specht, J., Egloff, B., \& Schmukle, S. C. (2011). Stability and change of personality across the life course: The impact of age and major life events on mean-level and rank-order stability of the Big Five. Journal of Personality and Social Psychology, 101, 862-882. doi:10.1037/a0024950

Spithoven, A. W. M., Bijttebier, P., \& Goossens, L. (2017). It is all in their mind: A review on information processing bias in lonely individuals. Clinical Psychology Review, 58, 97-114. doi:10.1016/j.cpr.2017.10.003

Stephan, Y., Sutin, A. R., \& Terraciano, A. (2014). Physical activity and personality development across adulthood and old age: Evidence from two longitudinal studies. Journal of Research in Personality, 49, 1-7. doi:10.1016/j.jrp.2013.12. 003

Stokes, J. P. (1985). The relation of social network and individual difference variables to loneliness. Journal of Personality and Social Psychology, 48, 981-990. doi:10. 1037/0022-3514.48.4.981

Teppers, E., Klimstra, T. A., van Damme, C., Luyckx, K., Vanhalst, J., \& Goossens, L. (2013). Personality traits, loneliness, and attitudes towards aloneness in adolescence. Journal of Social and Personal Relationships, 30, 1045-1063. doi:10. $1177 / 0265407513481445$ 
van der Aa, N., Overbeek, G., Engels, R. C. M. E., Scholte, R. H. J., Meerkerk, G.-J., \& van den Eijnden, R. J. J. M. (2009). Daily and compulsive internet use and well-being in adolescence: A diathesis-stress model based on big five personality traits. Journal of Youth and Adolescence, 38, 765-776. doi:10.1007/s10964-0089298-3

van Roekel, E., Ha, T., Scholte, R. H. J., Engels, R. C. M. E., \& Verhagen, M. (2016). Loneliness in the daily lives of young adults: Testing a socio-cognitive model. European Journal of Personality, 30, 19-30. doi:10.1002/per.2028

Vanhalst, J., Goossens, L., Luyckx, K., Scholte, R. H. J., \& Engels, R. C. M. E. (2013). The development of loneliness from mid- to late adolescence: Trajectory classes, personality traits, and psychosocial functioning. Journal of Adolescence, 36, 1305-1312. doi:10.1016/j.adolescence.2012.04.002

Vanhalst, J., Klimstra, T. A., Luyckx, K., Scholte, R. H. J., Engels, R. C. M. E., \& Goossens, L. (2012). The interplay of loneliness and depressive symptoms across adolescence: Exploring the role of personality traits. Journal of Youth and Adolescence, 41, 776-787. doi:10.1007/s10964-011-9726-7

Vanhalst, J., Soenens, B., Luyckx, K., van Petegem, S., Weeks, M. S., \& Asher, S. R. (2015). Why do the lonely stay lonely? Chronically lonely adolescents' attributions and emotions in situations of social inclusion and exclusion. Journal of Personality and Social Psychology, 109, 932-948. doi:10.1037/pspp0000051

Victor, C. R., Grenade, L., \& Boldy, D. (2005). Measuring loneliness in later life: A comparison of differing measures. Reviews in Clinical Gerontology, 15, 63-70. doi:10.1017/S0959259805001723

Wortman, J., Lucas, R. E., \& Donnellan, M. B. (2012). Stability and change in the big five personality domains: Evidence from a longitudinal study of Australians. Psychology and Aging, 27, 867-874. doi:10.1037/a0029322

Zhong, B.-L., Chen, S.-L., Tu, X., \& Conwell, Y. (2016). Loneliness and cognitive function in older adults: Findings from the Chinese Longitudinal Healthy Longevity Survey. The Journals of Gerontology Series B: Psychological Sciences and Social Sciences, 72, 120-128. doi:10.1093/geronb/gbw037

Zvolensky, M. J., Taha, F., Bono, A., \& Goodwin, R. D. (2015). Big five personality factors and cigarette smoking: A 10-year study among US adults. Journal of Psychiatric Research, 63, 91-96. doi:10.1016/j.jpsychires.2015.02.008 